\title{
Minimally Invasive Carpal Tunnel Release
}

* Corresponding Author:

Amro Ahmed Fouaad Attia amrfouad1980@yahoo.com

Received for publication April 5, 2021; Accepted June 29, 2021; Published online June 29, 2021, 2021.

Copyright The Authors
published by Al-Azhar
University, Faculty of Medicine,
Cairo, Egypt. Users have the
right to read, download, copy,
distribute, print, search, or link
to the full texts of articles under
the following conditions:
Creative Commons Attribution-
Share Alike 4.0 International
Public License (CC BY-SA 4.0).
doi: 10.21608/aimj.2021.68931.1443.
${ }^{1 .}$ Orthopedic Department, Faculty of
Medicine, Al-Azhar University,
Cairo, Egypt.

Amro Ahmed Fouaad Attia, ${ }^{1}$ MD.

\begin{abstract}
Background: The surgical therapy modalities for carpal tunnel syndrome, vary from open transverse carpal ligament release TCLR, to different surgical treatment options, Minimal invasive release, endoscopic release, and sonographically guided release, with no consensus about any of them.

Aim of the study: To evaluate the end results and efficacy after minimally invasive carpal tunnel syndrome.

Patients and Methods: Twenty patients with severe carpal tunnel syndromes, were treated at Al-Azhar University Hospitals between 20152017, with percutaneous technique, will be described in detail. There were 2 males and 18 females, 45.9 years of age on average with an average follow-up of about 12 months.

Results: All patients were satisfied except three patients. two of them suffered from recurrence and one from scar formation. There was no difficulty with this technique for all patients except for one female patient with marked obesity. In our study, we will compare our results to the open technique. No adjacent structures were damaged.

Conclusion: This study demonstrated that minimal invasive carpal tunnel release is potentially a safe, secure, quick, and effective procedure to transect the transverse carpal ligament and may be an alternative option to traditional surgical treatment of carpal tunnel syndrome and need more accurate knowledge of district anatomy and more experience.

Keywords: Carpal tunnel ;Transverse carpal Ligament; Median nerve; Minimal invasive release.
\end{abstract}

Disclosure: The authors have no financial interest to declare in relation to the content of this article. The Article Processing Charge was paid for by the authors.

Authorship: All authors have a substantial contribution to the article.

\section{INTRODUCTION}

All age groups can complain from carpal tunnel syndrome symptoms, especially middle-aged women, the compression may be due to internal causes from tenosynovitis, external cause from transverse carpal ligament, and general causes affecting neural tissue. Nerve conduction studies confirm the diagnosis. ${ }^{1}$

The surgical therapy modalities for carpal tunnel syndrome, varies from the standard open release of the transverse carpal ligament $\mathrm{TCL}^{2}$ to different challenging surgical treatment options (minimal invasive release of carpal tunnel syndrome, ${ }^{3}$ endoscopic release of carpal tunnel syndrome, ${ }^{4}$ and Sonographically directed percutaneous needle release of carpal tunnel syndrome, ${ }^{5}$ with no consensus about any of them. ${ }^{6}$

The main concern of open release treatment is the high success rates and reduced postoperative morbidity. However; There are complications such as pillar pain, ${ }^{7}$ scar discomfort ${ }^{8}$, changes in grip and pinch strength. ${ }^{9}$ Therefore, minimally invasive carpal tunnel release is effective and safe surgical procedure that can mitigate incision-induced scars pillar pain must be developed, allowing an early return to pre-surgical activities and early grip healing, pinch strength, and lower scar tenderness. ${ }^{10}$

\section{PATIENTS AND METHODS}

This study was accepted by our institution's institutional review board, and each patient's informed consent has been obtained. All patients had scheduled for surgical intervention after the failure of conservative therapy in the form of antiinflammatory, analgesic, splinting, and local injection. (Twenty patients) with severe carpal tunnel syndromes treated in Hand and Microsurgery Unit, Orthopedic department, Al-Azhar University Hospitals from 2015-2017 using the presented percutaneous technique, by a single surgeon. With a median age of 45.9 years, there were 2 males and 18 females. The main causes of carpal tunnel syndromes are idiopathic (no general cause), 4 smokers, out of 20 patients. All of the patients had a history of local 
corticosteroid injection as the first line of treatment. 11

The carpal tunnel syndromes were diagnosed by continuous tingling and numbness sensation of the fingers, And clumsy Hand, ${ }^{12}$ with positive tinsels sign, Phalen's test, and compression test. ${ }^{13}$ Nerve conduction test is important as a medico-legal test, to confirm the diagnosis and to exclude cervical cause. ${ }^{14}$ The inclusion criteria of this study were severe carpal tunnel syndromes, with positive NCV and or EMG after the failure of conservative treatment. Exclusion criteria were, patients with pathology are cervical origin, age under 18 years old, post-traumatic carpal tunnel syndrome, recurrent carpal tunnel syndrome, and pregnancy.

\section{Operative technique}

All patients had been surgery under local anesthesia using a tourniquet with pressure between 200 and $2500 \mathrm{mmHg}$. Supine position, precise knowledge of district anatomy is necessary for good surgery with this technique, in particular, the identification of the so-called secure canal in the carpal tunnel, in which some landmarks guided to the safe canal, volar proximal crease of the wrist, Palmaris longus tendon, cardinal line of Kaplan, distally to it can draw the skin projection of the superficial palmar arch. All are to a safe superficial palmar branch of median nerve protection at the radial side, the ulnar neurovascular system at the ulnar side, and distally to protect superficial palmar Vascular arch. (Figure 1).

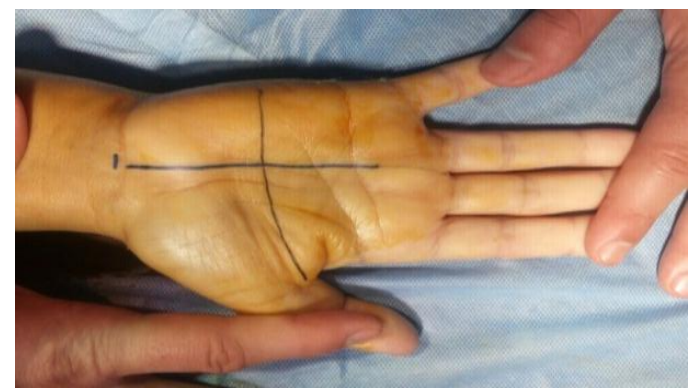

Fig 1: picture showing incision landmarks.

Transverse incision $0.5-1 \mathrm{~cm}$ on the flexion proximal crease of the wrist (Figure 2), the crease was dissected, the incision was expanded across the tendon of the Palmaris longus, and caution was taken while conducting the resection to prevent injury to the cutaneous branch, dissecting the deep fascia to reach the proximal border of the transverse carpal ligament. After which free dilator below the TCL surface (Figure 3), longitudinal dissection of TCL by dilator to made a safe tunnel, followed by removal of the dilator and introduce the protector (Figure 4), and finally resection of the TCL (Figure 5), which could be verified by testing against the median nerve, that is surrounded by synovium and tendons, using bluntly terminated Metzenbaum scissors, which are slowly distal to proximal resections to the TCL. The maximum distance was reached at the meeting point of two longitudinal lines from the third web and cardinal line of Kaplan, eventually to guarantee that the TCL was fully resected, determining that there was no resistance by vertically testing the tip of the Metzenbaum scissors over the TCL.

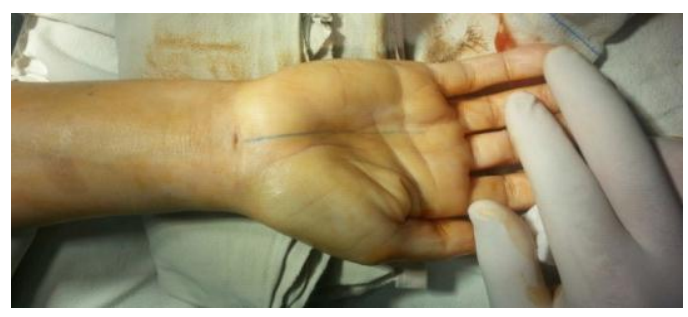

Fig 2: Picture showing incision at wrist crease.

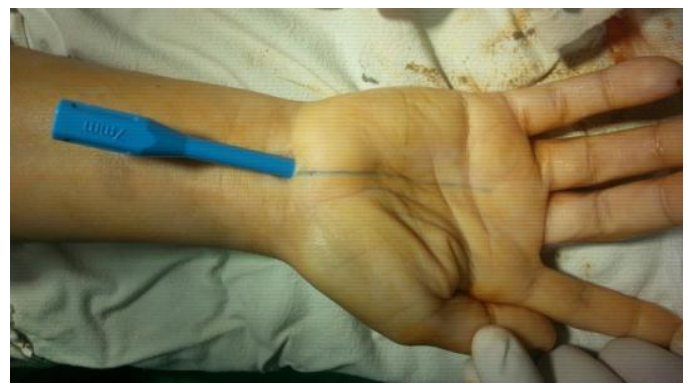

Fig 3: Picture showing free dilator.

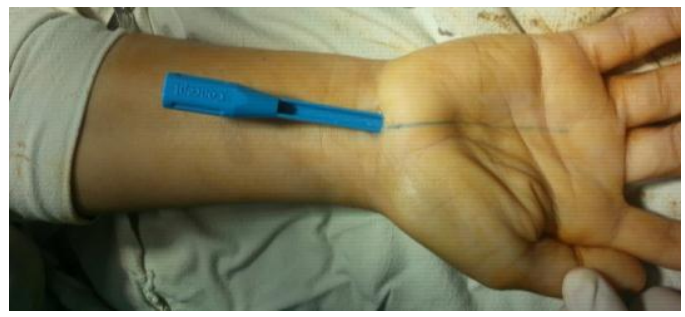

Fig 4: Picture showing protector insertion.

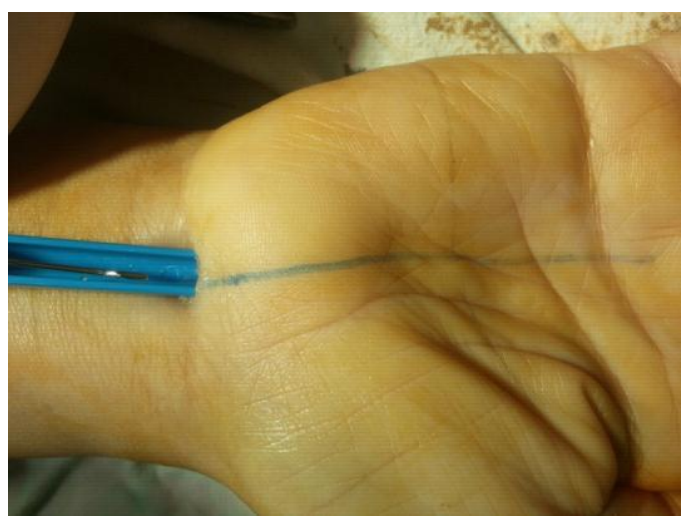

Fig 5: Picture showing release of the TLC.

After complete resection of TCL, irrigation of the incision, followed by the closure of the skin by interrupted suture with blue nylon 5-0 (Figure 6), the bulky dressing was done with mild compression and splint application in the position of mild wrist extension. Stichew were removed around 10 to 15 dayed. Follow up of all patients at our institute, after 
one week, 2 weeks, 3 months, 6 months, and 12 months.

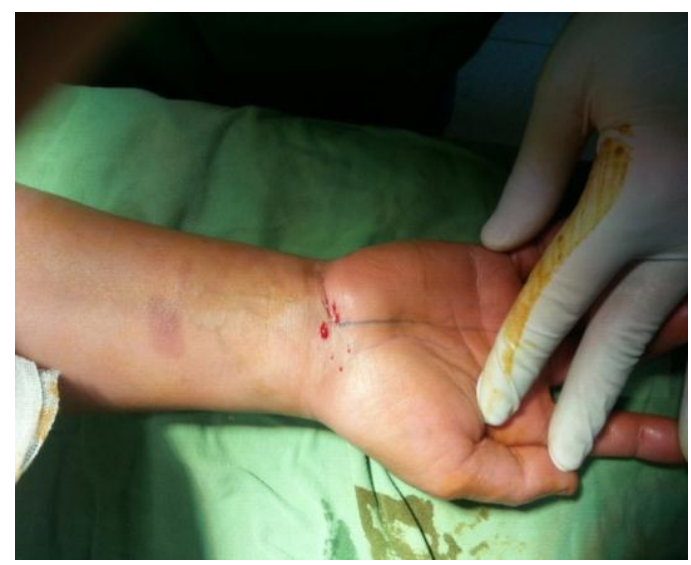

Fig 6: Picture showing closure of the wound.

\section{RESULTS}

This technique is a minimally invasive incision of the distal wrist crease with an average scar of about 1 $\mathrm{cm}$, at the proximal palmar crease level, so there were no hand contacts at this area and no scar discomfort. For 17 patients $85 \%$ had full transverse carpal ligament division with no complications, two of the remaining 3 patients $15 \%$ had recurrence owing to incomplete transverse carpal ligament division, and one of the patients had a hypertrophic scar and no adjacent structures were damaged. There was no difficulty with this technique for all patients except one female patient with marked obesity, with difficulty in a dissection of TCL. Time to complete the procedure was an average of 10-15 minutes and time to return not heavy work was 7-10 days with an average following of 24 months. At the end of follow up period according to the pain scale and DASH Score, there are twelve patients $60 \%$ obtained excellent results, two patients $10 \%$ was very satisfied, three of the patients $15 \%$ were good, and three patients $15 \%$ was poor findings.

\section{DISCUSSION}

Carpal tunnel syndrome CTS being one of the most popular neuropathies involving the peripheral nerves and is the upper limb's most frequent nerve trapping syndrome. It affects $1 \%$ of the population and most commonly happens between middle-aged women. ${ }^{15}$ Learmonth in 1933 identified the conventional carpal tunnel release. ${ }^{6}$ Traumatic wound, delayed wound healing, pillar syndrome was identified as complications referring to pain over the thenar and hypothenar area resulting from skin and subcutaneous loss and nerve and vessel injuries. ${ }^{16}$ In this study we have a good result resulting from the incision are out of contact palm area and no scar formation or discomfort In early 1980, minimal techniques for overcoming the issue of open surgery were implemented with an endoscope. ${ }^{4}$ The increases the length of the operation and additional training and equipment are required for the surgeon to operate. ${ }^{17}$ Total resection of TLC is the currently accepted standard therapy. ${ }^{18}$ Nonetheless, these traditional surgical procedures involve a significant opening of the skin and internal structure, putting sufferers at high risk of forming scars and discomfort following surgery. In addition, nerve dislocation is caused by the postoperative increase in space within the carpal tunnel and the development of scars, leading to postoperative complications such as Flexors anterior draw, pain at the surgical site, and handgrip loss, Cellocco et al ${ }^{19}$ regarding operative time, in our study we have a short time and short time to work return without any case of flexor anterior draw or nerve translation or dislocation. Hamed and Harfoushi recorded the carpal tunnel release by the mini-open technique. Nevertheless, various validation approaches have been used for the full resection of TCL in this study than in previous studies. Utilizing an anatomical examination, the current study demonstrates that TCL fasciotomy with minimally invasive distal wrist crease insertion is a secure surgical technique that does not harm the surrounding structure. In addition, this study stresses that the thickest portion of TCL is extremely necessary to ensure surgical release. ${ }^{3}$ Fourteen slightly embalmed cadaveric distal forearm samples identified by Markison RE, et al ${ }^{20}$ are subjected to the US main landmarks recognition, TCTR method, and dissection post-TCTR. Interesting result measurements were the correspondence among main landmarks defined on the US and anatomical structures revealed by dissection (median nerve and 4 bony pillars of transverse carpal ligament), Transected transverse carpal ligament percentage, and transection position frequency of damage to neighboring structures, time to completion of the process and technical difficulty evaluation by the operator of each TCTR procedure and they found that the anatomical dissection nearly corresponded exactly to the skin marks that delineated the location of US-visualized landmarks, nine $64.2 \%$ of 14 samples had full transverse carpal ligament division. An average of $68.8 \%$ of the ligament was transected in the remaining 5 samples. No adjacent structures were damaged, with an average of $9.9 \pm 4.6$ minutes to complete the operation ${ }^{20}$ in our study we follow the anatomical dissection by palpation of carpal tunnel boundaries, draw a line to follow, and prevent damage of the neighboring important structure.

We have some limitations in this thiesis, efficacy was measured only by the patient-reported system and pain scale, other measures like atrophy, grip strength, and caparison to the contralateral side, Follow up by MRI or NCV to confirm complete dissection of the TCL should be added. Furthermore, this is a single operator cohort study that needs to be evaluated and confirmed by a randomized multicenter controlled trial to evaluate the efficacy and safety of ETCLR versus endoscopic or open carpal tunnel release.

\section{CONCLUSION}

In This study, we have a good outcome of Minimally invasive CTR with successful results, involves smaller incisions made within the carpal tunnel from the center of the palm and the TCL division, preserving the superficial and deep structures intact 
and leading to less soft tissue dissecting, fewer pain and shorter healing time, With minimal complications.

\section{REFERENCES}

1. Eversman WW. Entrapment and compression neuropathies. In: Green DP, ed. Operative Hand Surgery. New York: Churchill-Livingstone, 1993.

2. Kim DH. Carpal tunnel syndrome: open carpal tunnel release. J Korean Neurotraumatol Soc. 2008; 4:1-7.

3. Hamed SA, Harfoushi FZ. Carpal tunnel release via mini-open wrist crease incision: procedure and results of four years clinical experience. Pak J Med Sci. 2006; 22:367-72.

4. Agee JM, Peimer CA, Pyrek JD, et al. Endoscopic carpaltunnel release: a prospective study of complications and surgicalexperience. $J$ Hand Surg (Am). 1995; 20:165-71.

5. McShane JM, Slaff S, Gold JE, et al: Sonographically guided percutaneous needle release ofthe carpal tunnel for treatment of carpal tunnel syndrome: preliminary report. $J$ Ultrasound Med. 2012;31:1341-9.

6. Learmonth JR. The principle of decompression in the treatment ofcertain diseases of peripheral nerves. SurgClin North Am. 1933; 13:905-13.

7. Eversmann WW. Entrapment and compression neuropathies.In: Green DP (ed) Operative Hand Surgery,2nd ed, Churchill Livingstone, New York. 1988; 1423- 78 .

8. Bedeschi P. Complicanze postoperatorie correlatealla sezione e/o alla cicatrizzazione del legamento traversodel carpo nella chirurgia della sindrome del tunnel carpalee loro prevenzione. Ortop Traumatol. 2002; 44: 30-4.

9. Bednarski M, Zyluk A and Zyluk B. Changes of grip and pinch strength after carpal tunnel release. Chir Narzadow Ruchu Ortop Pol. 2005; 70:21-6.

10. Sayegh ET and Strauch RJ. Open versus endoscopic carpal tunnel release: a metaanalysis of randomized controlled trials. ClinOrthopRelat Res. 2015; 473:1120-32

11. Peters-Veluthamaningal C, Winters JC, Groenier $\mathrm{K}$, et al. Randomised controlled trial of local corticosteroid injections for carpal tunnel syndrome in general practice. BMC FamPract. 2010; 11:54.

12. Papanicolaou GD, McCabe SJ and Firrell J. The prevalence and characteristics of nerve compression symptoms in the general population .$J$ Hand Surg. 2001; 26:460-6

13. Graham B, Regehr G, Naglie G, et al. Development and validation of diagnostic criteria for carpal tunnel syndrome. J Hand Surg Am. 2006; 31:919-24.

14. Taylor-Gjevre RM, Gjevre JA and Nair B. Suspected carpal tunnel syndrome. Do nerve conduction study results and symptoms match? Canadian FamPhysician. 2010, 56:250-4.

15. Szabo RM. Carpal tunnel syndrome. In: Gelberman RH, ed. Operative Nerve Repair and Reconstruction. Philadelphia, PA: JB Lippincott. 1991: 869-88.
16. Okutsu I, Nimomiya S, Takotori $\mathrm{Y}$, et al. Endoscopic managementof carpal tunnel syndrome. Arthroscopy. 1989; 5:11-8.

17. Lee DH, Masear VR, Meyer RD, et al. Endoscopic carpal tunnel release: a cadaveric study. J Hand Surg Am. 1992; 17: 1003-8.

18. Palmer DH, Paulson JC, Lane-Larson CL, et al. Endoscopic carpal tunnel release: a comparison of two techniques with open release. Arthroscopy. 1993; 9:498-508.

19. Cellocco P, Rossi C, Bizzarri F, et al. Mini-open blind procedure versus limited open technique for carpal tunnel release: a 30-month follow-up study. J Hand Surg Am. 2005; 30:493-9.

20. Markison RE: Percutaneous ultrasound-guided MANOS carpal tunnel release technique. Hand (N Y). 2013;8:445-9. 